\title{
Prevalence, patterns and predictors of depression treatment among community- dwelling older adults with stroke in the United States: a cross sectional study
}

\author{
Sandipan Bhattacharjee ${ }^{*}$, Majed Al Yami², Sawsan Kurdi ${ }^{2}$ and David Rhys Axon ${ }^{1}$
}

\begin{abstract}
Background: Depression is one of the most common psychiatric conditions among stroke survivors and is associated with several negative health outcomes. However, little is known about the depression treatment patterns among stroke survivors. The objective of this study was to examine national-level prevalence, patterns and predictors of depression treatment among community-dwelling stroke survivors.

Methods: This study adopted a retrospective, cross-sectional study design using multiple years of Medical Expenditure Panel Survey (MEPS) (2002-2012) data. The study population consisted of older adults (age $\geq 50$ years) who (i) were stroke survivors (ICD-9-CM codes of 430-438), (ii) did not die during the calendar year, and (iii) had co-occurring depression (ICD-9-CM code of 296.xx, or 311.xx). Depression treatment, identified by antidepressant medication and/or psychotherapy use, was the dependent variable of this study. Multinomial logistic regression analysis was conducted to examine the association of individual level factors with depression treatment among stroke survivors with co-occurring depression.

Results: The final study sample consisted 370 (unweighted) community-dwelling older adults with self-reported stroke and depression. The prevalence of co-occurring depression among stroke survivors was 22.03\% [95\% Confidence Interval (CI) 19.7-24.4\%]. An overwhelming majority (87.6\%) of stroke survivors with co-occurring depression reported some form of depression treatment. Antidepressants only and combination therapy was reported by $74.8 \%(95 \% \mathrm{Cl}, 71.6-78.0 \%$ ] and $12.8 \%(95 \% \mathrm{Cl}, 10.5-15.1 \%)$ by stroke survivors with co-occurring depression respectively. Approximately, $61 \%$ of stroke survivors with co-occurring depression reported using SSRIs, followed by SNRIs (15.2\%), miscellaneous antidepressants (12.1\%), TCAs (9.8\%), phenylpiperazine antidepressants (5.2\%), and tetracyclic antidepressants (4\%). Sertraline (15.8, 95\% Cl, 12.7-19.0\%) had the highest reported use among individual antidepressants.

Conclusions: Vast majority (nearly 90\%) of the study sample received some form of depression treatment and several individual level factors (such as age, education) were associated with the report of depression treatment use. Future longitudinal studies are warranted to assess the comparative treatment benefits of antidepressants, psychotherapy and their combination. Healthcare providers should carefully assess the risks and benefits of antidepressant (such as SSRIs or TCAs) use in this vulnerable population prior to their use.
\end{abstract}

Keywords: Stroke, Depression, Antidepressants, Psychotherapy

\footnotetext{
* Correspondence: bhattacharjee@pharmacy.arizona.edu

${ }^{1}$ Department of Pharmacy Practice and Science, College of Pharmacy, The

University of Arizona, 1295 North Martin Avenue, Tucson, AZ 85721, USA

Full list of author information is available at the end of the article
}

(c) The Author(s). 2018 Open Access This article is distributed under the terms of the Creative Commons Attribution 4.0 International License (http://creativecommons.org/licenses/by/4.0/), which permits unrestricted use, distribution, and reproduction in any medium, provided you give appropriate credit to the original author(s) and the source, provide a link to the Creative Commons license, and indicate if changes were made. The Creative Commons Public Domain Dedication waiver (http://creativecommons.org/publicdomain/zero/1.0/) applies to the data made available in this article, unless otherwise stated. 


\section{Background}

Stroke is a common and costly disease, which is a major burden on patients' lives and the health system economy. On average, every $40 \mathrm{~s}$, someone in the United States (US) has either a new or recurrent stroke, with an annual incidence of 795,000 [1]. Other than being the fifth leading cause of mortality, stroke is the leading cause of long-term adult disability in the US [1]. Due to advances in awareness, risk factor control, and the aging population, stroke survivors' prevalence has been increasing [1]. However, recovery after stroke takes time, and usually stroke survivors live with some degree of functional disability and depression is a common sequelae after stroke [2]. A pooled estimate indicates that depressive symptoms are present in one third of all stroke survivors at any time during the follow-up [3]. Another study reported that pooled prevalence of minor and major depression in community based setting after stroke are 9 and 14\%, respectively [4].

Co-occurring depression among stroke survivors is associated with poor rehabilitation outcome [5], compromised quality of life [6], social isolation, poor medications adherence [7], and higher rate of mortality [8]. Given the array of negative outcomes associated with co-occurring depression among stroke survivors, it is critical to treat depression in this vulnerable population, which in turn may improve patients' health outcomes and quality of life. In general, depression can be treated by using antidepressants, psychotherapy, or both. Existing randomized controlled trials (RCTs) have demonstrated the benefits of these depression treatment modalities in reducing depression burden among stroke survivors [9-14]. Moreover, in a Cochrane review of 12 clinical trials, the use of antidepressant treatment in older adults(age range of 60-78), was associated with an improvement in rates of depression (OR 0.47, 95\% CI 0.22-0.98) [15]. A recent systematic review and meta-analysis of RCTs investigating the effectiveness of antidepressants in poststroke depression found a standardized mean effect size of $-0.96(95 \% \mathrm{CI}=-1.41,-0.51)$ between antidepressants versus placebo, indicating a significant advantage of antidepressants over placebo $(p<0.0001)$ [16]. Furthermore, Mitchell et al. found that a combination of antidepressant and behavioral therapy was more effective in reducing depression compared to antidepressants alone [11].

Despite the evidence of the efficacy of depression treatment modalities (antidepressants only, psychotherapy only, and antidepressant and psychotherapy combination) ", to the best of our knowledge, no study to date has been conducted to examine the national-level prevalence, patterns and predictors of depression treatment among community-dwelling stroke survivors with co-occurring depression in the United States (US). Examining the current treatment patterns can help to understand whether the demonstration of depression treatment efficaciousness among stroke survivors from RCTs have helped in adoption of depression treatment into real-world clinical practice. Moreover, determining the predictors of depression treatment among stroke survivors can provide insights into factors where there is/are need of intervention(s) to improve depression care. Hence, this study is a first of its kind to examine national-level prevalence, patterns and predictors of depression treatment among community-dwelling stroke survivors in the US.

\section{Methods}

\section{Study design}

We adopted a retrospective, cross-sectional study design using pooled data from Medical Expenditure Panel Survey (MEPS) (2002-2012). Respondents of the MEPS are followed for two years. In order to eliminate the chances of including the same respondent between consecutive years, we used alternate years of data (2002, 2004, 2006, 2008, 2010, and 2012) [17]. It is recommended that multiple years of MEPS data be used to achieve adequate sample size [18].

\section{Data source}

MEPS is a nationwide survey of US citizens, their healthcare providers and employers which records healthcare cost, use and insurance coverage [19], collected by the Agency for Healthcare Research and Quality (AHRQ). MEPS uses the sampling framework of the National Health Interview Survey (NHIS) and contains information about medical and mental health conditions, as well as services and treatments such as prescription drugs and counseling therapies. The survey oversamples minority groups and disabled people in order to achieve nationally representative estimates. The survey consists of a household component (MEPS-HC) and an insurance component (MEPS-IC). The MEPS-HC uses a nationally representative sample panel of households selected annually whereby household respondents provide information about their medical conditions. This information is then converted into International Classification of Diseases, 9th Edition, Clinical Modification (ICD-9-CM) codes and clinical classification codes by professional coders. Data in each panel are collected for two calendar years. Information from MEPS-HC was used to obtain data of selfreported medical conditions and socio-demographic data. The MEPS-IC is conducted by the U.S. Census Bureau and contains information on establishment characteristics, whether an establishment offers health insurance, and details on health plans. Household respondents medical conditions have been found to typically correlate with medical care provider data. It has been demonstrated that 
MEPS participant reported conditions are consistent with those provided by their medical providers for chronic conditions (such as diabetes, mental health, hypertension) with a median sensitivity of 70\% [20]. The MEPS Medical Conditions file was used to identify the comorbidities, the Prescription Use file was used to identify the medication use, and Outpatient and Office-based Provider Visits files were used to identify psychotherapy use [19].

\section{Study population}

The study population consisted of older adults (age $\geq$ 50 years) who (i) were stroke survivors, (ii) did not die during the calendar year, and (iii) had co-occurring depression. Stroke was identified by using International Classification of Diseases, Ninth Revision, Clinical Modification (ICD-9-CM) code of 430.xx-438.xx [21]. These ICD-9-CM codes are used by the American Heart Association to report stroke statistics [22] and have also shown high sensitivity ( $\geq 82 \%)$, specificity ( $\geq 95 \%)$, and positive predictive value ( $\geq 81 \%$ ) to identify overall diagnosis of acute or preexisting stroke [23]. Co-occurring depression was identified by using ICD-9-CM code of 296.xx, or 311.xx [24]. As MEPS publically available medical conditions file provides only three digit ICD-9CM codes, there is a possibility of including some individuals with bipolar disorder with the use of ICD-9-CM code of 296.xx. However, it has been observed that most of the individuals with an ICD-9-CM code of 296. $\mathrm{xx}$ have major depressive disorder and overwhelming majority (>90\%) of them have an ICD-9-CM code of 311 that corresponds to unspecified depression [25]. Moreover, existing studies using MEPS data have used ICD-9-CM codes of 296.xx and 311.xx to identify depression $[26,27]$.

\section{Dependent variable}

Depression treatment constituted the dependent variable. Depression treatment was identified by antidepressant medication and/or psychotherapy use. Antidepressant use was ascertained from the prescription drug files. Multum Lexicon therapeutic class code (second level) of "249" was used to identify antidepressant use. The third level of Multum Lexicon therapeutic class codes were used to identify the subclasses of antidepressants. Antidepressants were classified into the following categories: (i) Selective serotonin reuptake inhibitors (SSRIs); (ii) Serotonin-norepinephrine reuptake inhibitors (SNRIs); (iii) Tricyclic antidepressants (TCAs); (iv) Monoamine oxidase inhibitor (MAO inhibitors); (v) phenylpiperazine antidepressants; (vi) Tetracyclic antidepressants; and (vii) Miscellaneous antidepressants. An additional file is provided showing detailed Multum Lexicon codes used to identify these subclasses of antidepressants [see Additional file 1: Table S1]. National Drug Codes (NDCs) were used to identify individual antidepressants. Psychotherapy use was obtained from the provider visits of outpatient and officebased files. Stroke survivors with co-occurring depression, who reported at least one visit for psychotherapy or mental health counseling services, were included in the group of psychotherapy receipt [28].

We defined depression treatment in two different ways. In the first measure, depression treatment was categorized as (i) receipt of antidepressants and/or psychotherapy; and (ii) no depression treatment. For the second measure, the depression treatment was classified into four groups: (i) antidepressant use alone; (ii) psychotherapy alone; (iii) antidepressant with psychotherapy; and (iv) no depression treatment. As the sample size of stroke survivors with co-occurring depression, who used psychotherapy alone (Unweighted $N=13$ ) was very small, they were not included in the final study sample.

\section{Independent variables}

This study was conceptualized using Ronal M. Andersen's Behavioral Model of Health Services Use framework to investigate the association between predisposing, enabling, need, external environmental, and personal health practices factors with depression treatment [29]. The predisposing factors included age (50-64 years, 65 years and older), gender (male; female), and race/ethnicity (white and others). Enabling factors included education (less than high school; up to high school; and higher than high school), marital status (married and others), type of insurance (public; private; and uninsured), and poverty status [poor or near poor $(<200 \%$ of federal poverty level); middle income or high income $(\geq 200 \%$ of federal poverty level)]. Need factors included chronic diseases (e.g. arthritis, osteoporosis, diabetes, thyroid disorder, heart disease, hypertension, asthma, gastro esophageal reflux disorder, depression, anxiety and other neurological conditions), limitations of activities of daily living (ADLs) (yes/no), limitations of instrumental activities of daily living (IADLs) (yes/no), activities limitations in work or housework (yes/ no), functional activities limitations (yes/no), perceived physical health status (excellent/very good; good; and fair/ poor), perceived mental health status (excellent/very good; good; and fair/poor), and pain (quite or extreme pain; moderate or little pain; and no pain). If a survey respondent required help or supervision on any of the ADLs (eating, dressing, bathing, toileting, getting in and out of bed, and mobility inside own residence) for at least another three months from the date of data collection (during any of the multiple interviews in a year), then they were considered to have ADL limitations. IADL limitations were defined similarly based on whether they required help or supervision with using the telephone, paying bills, taking medications, preparing light meals, 
doing laundry, or going shopping. MEPS participants were considered to have functional limitations if they had difficulties performing specific physical actions, or had problems with cognition, vision and hearing. The series of questions asked to evaluate difficulties with physical actions for at least three more months were: difficulty lifting 10 pounds, difficulty walking up 10 steps, difficulty walking 3 blocks, difficulty walking a mile, difficulty standing $20 \mathrm{~min}$, difficulty bending or stooping, difficulty reaching over head, difficulty using fingers to grasp. Cognitive limitations were identified with a "yes" response to any of the following questions: (i) experienced confusion or memory loss, (ii) had problems making decisions, or (iii) required supervision for their own safety. Vision or hearing problems were identified by asking the respondent whether they had difficulty seeing or hearing respectively. Activities limitation was identified based on whether MEPS participants had any limitation in work, housework, or school. Perceived physical and mental health status were collected during any of the interview rounds by asking MEPS respondents to rate their physical and mental health status into any of the following categories: excellent, very good, good, fair, and poor. Personal health practices consisted of body mass index (BMI) categories (under or normal; and overweight or obese), and smoking status (current smoker; and others). External environmental factors consisted of region (Mid-West; Northeast; West; and South), and metropolitan status (metropolitan; and non-metropolitan).

\section{Pain}

Antidepressants are prescribed at certain times to alleviate pain associated with different chronic conditions [30] and hence can influence depression treatment patterns among stroke survivors with co-occurring depression. In order to minimize the effect of pain on depression treatment among stroke survivors with co-occurring depression, we adjusted pain as one of the variables in the multivariate regression models. MEPS respondents were asked if - "During past 4 weeks, pain interfered with normal work outside the home and housework", which was used to construct the pain variable [31]. The pain variable was self-reported by MEPS respondents on a 5-point scale: (i) not at all; (ii) a little bit; (iii) moderately; (iv) quite a bit; and (v) extremely. We categorized pain into three categories for this study: (i) quite a bit/extreme pain; (ii) a little bit or moderate pain; and (iii) no pain.

\section{Statistical analysis}

Univariate analyses were conducted using chi-square tests to ascertain the statistically significant differences among different depression treatment groups (antidepressant use alone, antidepressant and psychotherapy combination and no depression treatment) in the study population. Multinomial logistic regression was conducted to assess the factors (predisposing, enabling, need, personal health choices, and external environmental factors) associated with depression treatment among stroke survivors with co-occurring depression. The levels of the depression treatment (dependent variable) consisted of: (i) antidepressant use alone; (ii) antidepressant and psychotherapy (combination therapy); and (iii) no depression treatment (which served as the reference group for the multinomial logistic regression). Sensitivity analyses was conducted by using logistic regression with any form of depression treatment (antidepressant and/or psychotherapy) compared to no depression treatment as dependent variable adjusting for predisposing, enabling, need, personal health practices, and external environmental factors. National estimates were obtained by adjusting for the complex survey design of MEPS. SAS version 9.4 (SAS institute Inc., Cary, NC, USA) was used to carry out all the analyses.

\section{Results}

The final study sample consisted 370 (unweighted) community-dwelling older adults with self-reported stroke and depression who were alive during the calendar year (2002, 2004, 2006, 2008, 2010, and 2012). The prevalence of co-occurring depression among stroke survivors was 22.03\% [95\% Confidence Interval (CI) 19.7-24.4\%]. An overwhelming majority $(87.6 \%)$ of stroke survivors with co-occurring depression reported some form of depression treatment. Antidepressants only and combination therapy was reported by $74.8 \%$ (95\% CI, 71.6-78.0\%] and $12.8 \%$ (95\% CI, 10.5-15.1\%) respectively by stroke survivors with co-occurring depression. Only $12.4 \%$ (95\% CI, 9.9-14.8\%) of stroke survivors with cooccurring depression reported that they did not receive any form of depression treatment.

Table 1 shows the overall distribution of predisposing, enabling, need, personal health practices and external environmental factors among stroke survivors with cooccurring depression as well as the distribution of these factors in different depression treatment groups. Overall, majority of stroke survivors with co-occurring depression were 65 years and older (60.4\%), females (62.4\%), whites $(77.3 \%)$, reported fair or poor perceived physical health status $(62.5 \%)$, experienced some form of pain (87.9\%), reported functional disability (89.8\%), had some chronic diseases $(66.2 \%)$, and resided in metropolitan area $(78 \%)$. From Table 1, it can be observed that there were subgroup differences in terms of age, race/ethnicity, education, poverty status, insurance, perceived mental health status, pain, ADL disability, chronic disease group, BMI status and region. For example, a 
Table 1 Descriptive Statistics of Stroke Survivors with Co-occurring Depression Medical Expenditure Panel Survey (2002-2012)

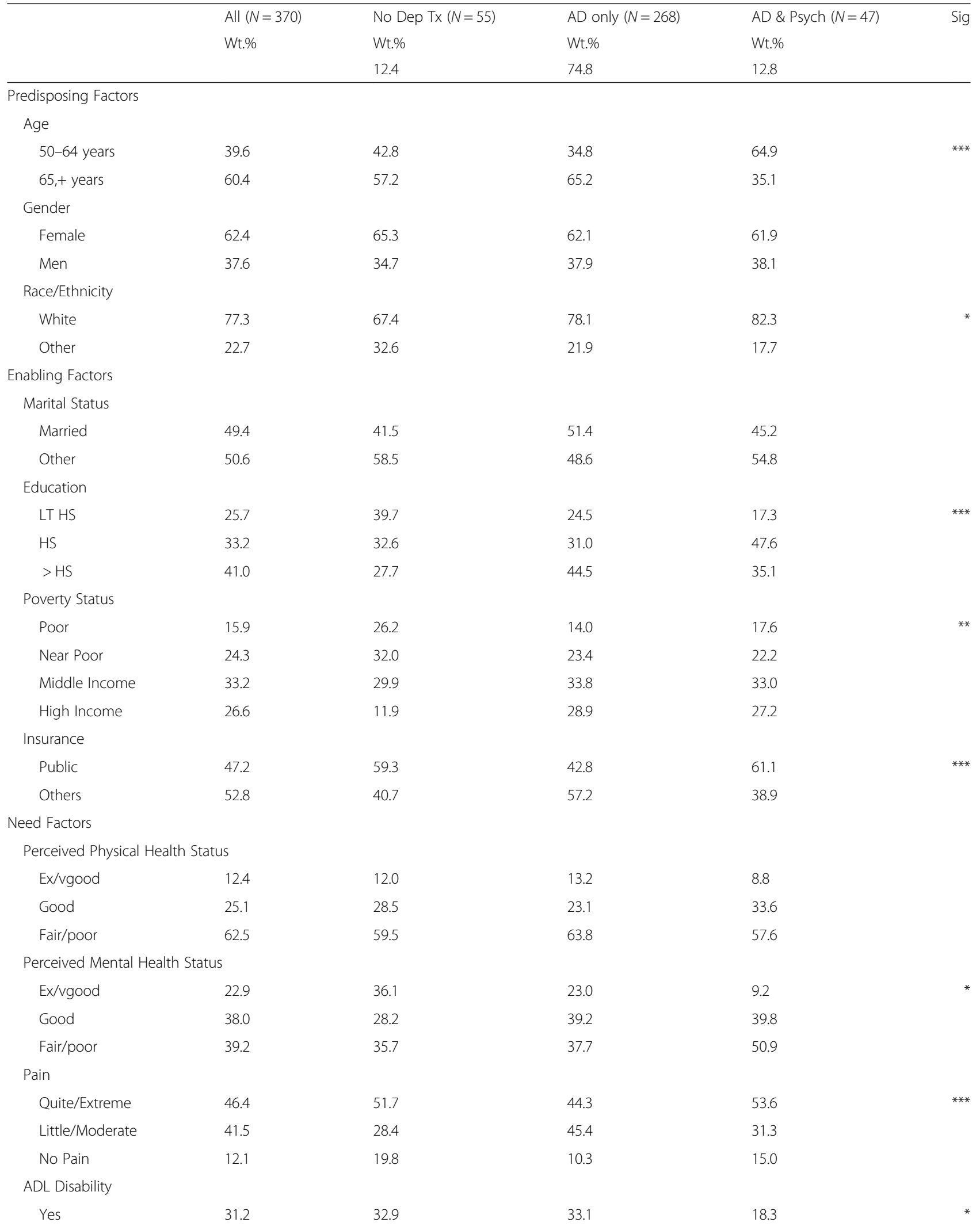


Table 1 Descriptive Statistics of Stroke Survivors with Co-occurring Depression Medical Expenditure Panel Survey (2002-2012) (Continued)

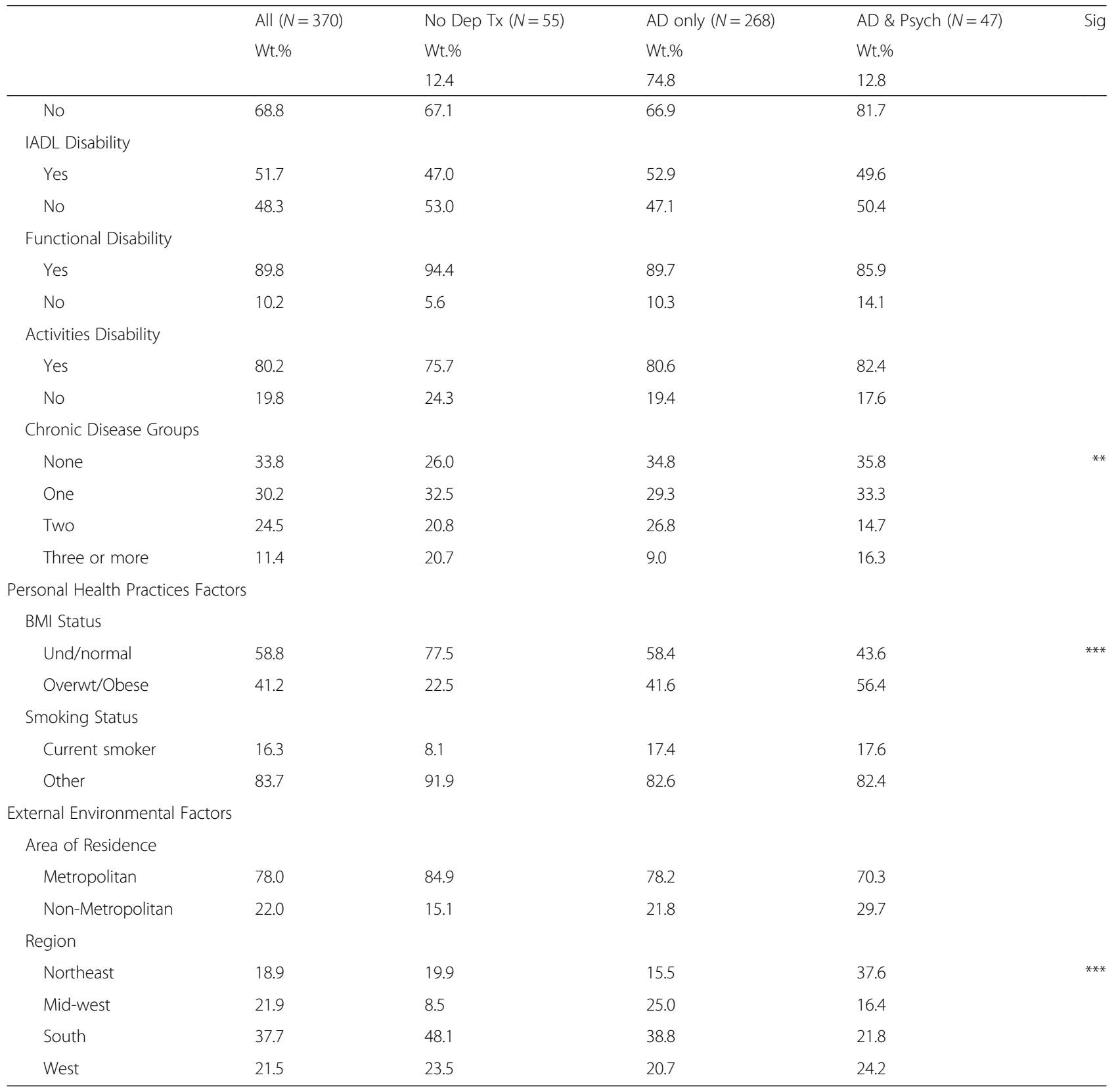

Based on 370 older adults (age $\geq 50$ years) with self-reported stroke and depression who were alive during the calendar year $(2002,2004,2006,2008,2010$, and 2012)

Abbreviations- No Dep Tx No Depression Treatment, AD only Antidepressants only, AD \& Psych Antidepressants with Psychotherapy, LT HS Less than High School, HS High School, Wt\% Weighted percentage, Sig Significant difference, Ex/vgood Excellent or Very Good, ADL Activity of Daily Living, IADL Instrumental Activity of Daily Living, Und/normal Underweight or Normal, Overwt/Obese Overweight or Obese, BMI Body Mass Index

Asterisks represent statistical significance between the different depression treatment groups [No Depression Treatment (Unweighted $\mathrm{N}=55$ ); Antidepressants only (Unweighted $\mathrm{N}=268$ ); and Antidepressants with Psychotherapy (Unweighted $\mathrm{N}=47$ )] based on chi-square tests

${ }^{* * *} p<0.001 ;{ }^{* *} 0.001 \leq p<0.01 ;{ }^{*} 0.01 \leq p<0.05$

greater proportion $(64.9 \%)$ of stroke survivors with cooccurring depression who received combination therapy were in the age range of 50-64 years, whereas the majority $(65.2 \%)$ of stroke survivors with cooccurring depression receiving antidepressants only were 65 years or older.
Table 2 provides the nationally representative patterns of depression treatment among stroke survivors with cooccurring depression. Approximately, $61 \%$ of stroke survivors with co-occurring depression reported using SSRIs, followed by SNRIs (15.2\%), miscellaneous antidepressants (12.1\%), TCAs (9.8\%), phenylpiperazine antidepressants 
Table 2 Dep Tx Patterns among Stroke Survivors with Co-occurring Depression Medical Expenditure Panel Survey (2002-2012)

\begin{tabular}{ll}
\hline & Wt.\% \\
\hline Any form of Dep Tx & 87.6 \\
SSRI & 60.9 \\
SNRI & 15.2 \\
TCA & 9.8 \\
PPAZ & 5.2 \\
Tetra CyC & 4.0 \\
Misc ADP & 12.1
\end{tabular}

Based on 370 older adults (age $\geq 50$ years) with self-reported stroke and depression who were alive during the calendar year (2002, 2004, 2006, 2008, 2010, and 2012) Abbreviations - Dep Tx Depression Treatment, SSRI Selective Serotonin Reuptake Inhibitor, SNRI Serotonin-Norepinephrine Reuptake Inhibitor, TCA Tricyclic Antidepressants, PPAZ Phenylpiperazine Antidepressants, Tetra Cyc Tetracyclic Antidepressants, Misc ADP Miscellaneous Antidepressants, Wt\% Weighted percentage (nationally representative)

Total number of individual antidepressant classes may not add up to $100 \%$ due to intra-class polypharmacy

Denominator for $\mathrm{Wt} . \%$ calculations for individual types of antidepressant classes was the total analytic sample (Unweighted $\mathrm{N}=370$ )

(5.2\%), and tetracyclic antidepressants (4\%). Sertraline (15.8, 95\% CI, 12.7-19.0\%) had the highest reported use among individual antidepressants (data not presented in table). Other individual antidepressant use in the study population that should be noted include citalopram (13.9, 95\% CI, 11.1-16.7\%), paroxetine (12.5, 95\% CI, 9.9-15.1\%), escitalopram (11.4, 95\% CI, $8.1 \%$ - 14.6), duloxetine (8.9, 95\% CI, 6.2-11.6\%), fluoxetine $(8.8,95 \%$ CI, $6.8-10.8 \%)$, bupropion $(8.6,95 \% \mathrm{CI}$, 7.2-10.1\%), venlafaxine (7.1, 95\% CI, 4.3-9.9\%), trazodone (6.6, 95\% CI, 4.8-8.4\%), amitriptyline (5.5, 95\% CI, 3.5-7.5\%) and mirtazapine (4.7, 95\% CI, $1.9 \%-7.4)$.

Table 3 summarizes the findings from the multinomial logistic regression analysis. Several individual-level factors were associated with depression treatment. For example, among stroke survivors with co-occurring depression, those who were 65 years and older were nearly six times more likely [Adjusted Odds Ratio (AOR): 5.80, 95\% CI 2.48-13.5] to report use of antidepressants only compared to those who were 50-64 years old. Stroke survivors with co-occurring depression who had less than high school education were 92\% (AOR: 0.08, 95\% CI 0.02-0.37) less likely to report the use combination therapy compared to those with higher than high school education. Details of the multinomial logistic regression are presented in Table 3 Sensitivity analyses with depression treatment (yes/no) showed similar findings (Table 4).

\section{Discussion}

The current study estimated the national level prevalence of co-occurring depression among communitydwelling older adults with stroke in the US to be $22.03 \%$. To the best of our knowledge, this is the first study to date to estimate the national-level prevalence of cooccurring depression among community-dwelling stroke survivors in the US. Data from existing studies showed that the prevalence of depression among individuals with stroke varied widely across the world based on the region and method used, ranging from 11 to $79 \%$ [32-43], with epidemiological studies showing the co-occurrence of depression in $30 \%$ of stroke cases [44]. A recent study by McCarthy et al. (2016) using data from the greater Cincinnati/Northern Kentucky stroke study in the US found that $37 \%$ of stoke survivors were at risk for depression at 3-months post-stroke [45]. Another recent study by Fei et al. (2016) using data from the Prevent Recurrent All-Inner city Stroke through Education (PRAISE) study of 556 individuals in New York City in the US found that $31 \%$ of stroke survivors had post stroke depression [46]. Prevalence of depression observed in our study was slightly lower compared to the available estimates from the recent US studies [45, 46], that can be explained by the fact that these are selfreported by MEPS respondents, which are often associated with stigma of reporting mental illnesses, as well as the possibility of under-diagnosis of depression. Another possible explanation can be that some stroke survivors may not recently report depressive symptoms as they may have been successfully treated and are currently in remission. However, depression can be episodic, so regular depression screening is recommended.

The current study also provides the first national-level estimate of the receipt of depression treatment among community-dwelling stroke survivors with co-occurring depression. Among individual antidepressant classes, the current study found that SSRIs were reported as the mostly used antidepressants, which is not surprising as SSRIs have been found to be effective among stroke survivors in reducing dependency, disability, neurological impairment, anxiety as well as depression [47]. Moreover, in a population-based nested case control study, SSRIs were not found to be associated with recurrent stroke risk [48]. However, this study [48] found that TCAs, were associated with $41 \%$ higher likelihood of stroke recurrence. According to the current study findings, TCAs were reported to be used by approximately $10 \%$ of the study sample, and given the risk of recurrent stroke, close monitoring should be in place for individuals on TCAs. Another advantage of using SSRIs among stroke survivors with depression is the potential benefit of decreasing platelet aggregation and adhesion. However, this benefit has been examined and observed among individuals with different conditions such as myocardial infarction, depression, and ischemic heart disease (with depression) but not among stroke survivors [49-51]. It should however be kept in mind that SSRIs do have significant side effects as demonstrated by a 
Table 3 Multinomial Logistic Regression among Stroke Survivors with Co-occurring Depression in terms of Depression Treatment Medical Expenditure Panel Survey (2002-2012)

\begin{tabular}{|c|c|c|c|c|c|c|}
\hline & \multicolumn{3}{|c|}{ AD Only $(N=268)$} & \multicolumn{3}{|c|}{ AD \& Psych $(N=47)$} \\
\hline & AOR & $95 \% \mathrm{Cl}$ & Sig & $\mathrm{AOR}$ & $95 \% \mathrm{Cl}$ & Sig \\
\hline \multicolumn{7}{|l|}{ Predisposing Factors } \\
\hline \multicolumn{7}{|l|}{ Age } \\
\hline $65,+$ yrs. vs $50-64$ yrs & 5.80 & {$[2.48,13.5]$} & $* * *$ & 1.16 & {$[0.42,3.18]$} & \\
\hline \multicolumn{7}{|l|}{ Gender } \\
\hline Female vs Men & 0.69 & {$[0.33,1.42]$} & & 0.53 & {$[0.21,1.31]$} & \\
\hline \multicolumn{7}{|l|}{ Race/Ethnicity } \\
\hline Other vs White & 1.60 & {$[0.77,3.32]$} & & 1.45 & {$[0.58,3.61]$} & \\
\hline \multicolumn{7}{|l|}{ Enabling Factors } \\
\hline \multicolumn{7}{|l|}{ Marital Status } \\
\hline Other vs Married & 1.02 & {$[0.45,2.31]$} & & 1.17 & {$[0.32,4.27]$} & \\
\hline \multicolumn{7}{|l|}{ Education } \\
\hline LT HS VS $>$ HS & 0.07 & {$[0.02,0.27]$} & $* * *$ & 0.08 & {$[0.02,0.37]$} & ** \\
\hline $\mathrm{HS}$ VS $>\mathrm{HS}$ & 0.24 & {$[0.08,0.75]$} & * & 0.57 & {$[0.13,2.53]$} & \\
\hline \multicolumn{7}{|l|}{ Insurance } \\
\hline Public vs others & 0.75 & {$[0.22,2.54]$} & & 3.54 & {$[0.65,19.2]$} & \\
\hline \multicolumn{7}{|l|}{ Poverty Status } \\
\hline Mid Inc./High Inc. vs Poor/Near Poor & 1.60 & {$[0.66,3.87]$} & & 3.90 & {$[1.19,12.8]$} & * \\
\hline \multicolumn{7}{|l|}{ Need Factors } \\
\hline \multicolumn{7}{|l|}{ Pain } \\
\hline Quite/Extreme vs No pain & 1.09 & {$[0.32,3.67]$} & & 1.02 & {$[0.22,4.68]$} & \\
\hline Little/Moderate vs No pain & 1.97 & {$[0.54,7.20]$} & & 1.11 & {$[0.23,5.33]$} & \\
\hline \multicolumn{7}{|l|}{ Perceived Physical Health Status } \\
\hline Good vs Ex/vgood & 0.49 & {$[0.08,2.93]$} & & 0.72 & {$[0.09,5.82]$} & \\
\hline Fair/poor vs Ex/vgood & 0.72 & {$[0.22,2.41]$} & & 0.19 & {$[0.06,0.60]$} & ** \\
\hline \multicolumn{7}{|l|}{ Perceived Mental Health Status } \\
\hline Good vs MH Ex/vgood & 4.55 & {$[2.26,9.15]$} & $* * *$ & 11.04 & {$[3.33,36.6]$} & $* * *$ \\
\hline Fair/poor vs MH Ex/vgood & 3.60 & {$[1.40,9.27]$} & $* *$ & 19.19 & {$[5.41,68.1]$} & $* * *$ \\
\hline \multicolumn{7}{|l|}{ ADL Disability } \\
\hline Yes vs No & 2.05 & {$[0.72,5.86]$} & & 0.39 & {$[0.11,1.34]$} & \\
\hline \multicolumn{7}{|l|}{ IADL Disability } \\
\hline Yes vs No & 1.57 & {$[0.52,4.78]$} & & 2.20 & {$[0.64,7.50]$} & \\
\hline \multicolumn{7}{|l|}{ Functional Disability } \\
\hline Yes vs No & 0.19 & {$[0.04,0.83]$} & * & 0.31 & {$[0.06,1.65]$} & \\
\hline \multicolumn{7}{|l|}{ Activities Disability } \\
\hline Yes vs No & 3.63 & {$[0.89,14.8]$} & & 3.73 & {$[0.71,19.6]$} & \\
\hline \multicolumn{7}{|l|}{ Chronic Disease Groups } \\
\hline One vs None & 0.54 & {$[0.17,1.69]$} & & 1.55 & {$[0.41,5.86]$} & \\
\hline Two vs None & 0.91 & {$[0.27,3.06]$} & & 1.33 & {$[0.36,4.89]$} & \\
\hline Three or more vs None & 0.19 & {$[0.07,0.48]$} & $* * *$ & 0.62 & {$[0.06,5.92]$} & \\
\hline \multicolumn{7}{|l|}{ CVD } \\
\hline Yes vs No & 0.02 & {$[0.00,1.34]$} & & 0.08 & {$[0.00,4.72]$} & \\
\hline
\end{tabular}


Table 3 Multinomial Logistic Regression among Stroke Survivors with Co-occurring Depression in terms of Depression Treatment Medical Expenditure Panel Survey (2002-2012) (Continued)

\begin{tabular}{|c|c|c|c|c|c|c|}
\hline & \multicolumn{3}{|c|}{ AD Only $(N=268)$} & \multicolumn{3}{|c|}{ AD \& Psych $(N=47)$} \\
\hline & $\mathrm{AOR}$ & $95 \% \mathrm{Cl}$ & Sig & AOR & $95 \% \mathrm{Cl}$ & Sig \\
\hline \multicolumn{7}{|l|}{ Anxiety } \\
\hline Yes vs No & 0.79 & {$[0.31,1.99]$} & & 1.09 & {$[0.40,2.93]$} & \\
\hline \multicolumn{7}{|l|}{ Hyperlipidemia } \\
\hline Yes vs No & 1.35 & {$[0.69,2.66]$} & & 2.73 & {$[0.94,7.96]$} & \\
\hline \multicolumn{7}{|l|}{ Personal Health Practices Factors } \\
\hline \multicolumn{7}{|l|}{ BMI Status } \\
\hline Overwt/Obese vs Und/normal & 5.18 & {$[1.93,13.8]$} & ** & 9.35 & {$[2.98,29.3]$} & $* * *$ \\
\hline \multicolumn{7}{|l|}{ Smoking Status } \\
\hline Curr smoker vs Other & 6.40 & {$[1.51,27.0]$} & * & 6.04 & {$[1.42,25.6]$} & * \\
\hline \multicolumn{7}{|l|}{ External Environmental Factors } \\
\hline \multicolumn{7}{|l|}{ Metropolitan Status } \\
\hline Non-Metropolitan vs Metropolitan & 1.53 & {$[0.67,3.46]$} & & 3.42 & {$[1.13,10.2]$} & * \\
\hline \multicolumn{7}{|l|}{ Region } \\
\hline Mid-west vs Northeast & 4.05 & {$[1.28,12.7]$} & * & 0.64 & {$[0.17,2.40]$} & \\
\hline South vs Northeast & 0.83 & {$[0.30,2.27]$} & & 0.20 & {$[0.06,0.63]$} & ** \\
\hline West vs Northeast & 0.53 & {$[0.12,2.37]$} & & 0.36 & {$[0.05,2.51]$} & \\
\hline
\end{tabular}

Based on 370 older adults (age $\geq 50$ years) with self-reported stroke and depression who were alive during the calendar year (2002, 2004, 2006, 2008, 2010, and 2012) Abbreviations -No Dep Tx No Depression Treatment, AD only Antidepressants only, AD \& Psych Antidepressants with Psychotherapy, LT HS Less than High School, HS High School, Wt\% Weighted percentage, Sig Significant difference, Ex/vgood Excellent or Very Good, ADL Activity of Daily Living, IADL Instrumental Activity of Daily Living, Und/normal Underweight or Normal, Overwt/Obese Overweight or Obese, BMI Body Mass Index, AOR Adjusted odds ratio, Mid Inc./High Inc. Middle Income or High Income

Asterisks represent statistical significance group differences by type of treatment compared to the reference group based on multinomial logistic regression. The reference group for the dependent variable in the multinomial logistic regression was "No Depression Treatment" $(N=55)$

${ }^{* * *} p<0.001 ; * * 0.001 \leq p<0.01 ;{ }^{*} 0.01 \leq p<0.05$

study among post-menopausal women using the Women's Health Initiative (WHI) data [52]. This study using the WHI data observed that even though the absolute event risks are low, SSRIs are associated with higher risk of death, and hemorrhagic and fatal stroke [52]. Hence, the benefits to risk profile should always be assessed before using these medications. It is noteworthy to mention that currently there are three ongoing trials (FOCUS, AFFINITY, and EFFECTS) examining the effect of fluoxetine $20 \mathrm{mg}$ daily for six months on different outcomes (such as modified Rankin scale, diagnosis of depression and adherence to medication) among stroke survivors [53]. Furthermore, there is an ongoing realworld study funded by the Patient Centered Outcomes Research Institute (PCORI) assessing the effectiveness of antidepressants among stroke survivors [54]. Findings from these studies have the potential to provide further evidence of antidepressant safety and effectiveness among stroke survivors.

Sertraline was the most frequently used individual antidepressant in this study sample. An open-label study [55] among stroke survivors with depression found that symptoms of depression and anxiety had consistent decline along with improvement in cognitive and functional performances with sertraline treatment and hence findings from this study are unsurprising. Approximately $14 \%$ of the current study sample reported using citalopram, which can be explained in the light of fewer side effects observed with citalopram in stroke survivors with depression [56], as well as the chances of significantly improving dexterity [57] after stroke. However, use of some individual antidepressants such as trazodone, mirtazapine and venlafaxine warrants constant monitoring as they have been observed to be associated high risks of several adverse events [58]. This study observed psychotherapy with antidepressant use in only $12.8 \%$ of stroke survivors with co-occurring depression. Even though specific data of the prevalence of psychotherapy use among stroke survivors is not available, but an existing study among depressed Medicare beneficiaries during 1992-1999 found psychotherapy use among a quarter of these patients [59]. However, the lower use of psychotherapy observed in the current study can be explained by the decline of outpatient psychotherapy in general population [60] as well as concerns about psychotherapy effectiveness among stroke survivors [61]. Selection of 
Table 4 Logistic Regression among Stroke Survivors with Co-occurring Depression in terms of Depression Treatment Medical Expenditure Panel Survey (2002-2012)

\begin{tabular}{|c|c|c|c|}
\hline & $\mathrm{AOR}$ & $95 \% \mathrm{Cl}$ & Sig \\
\hline \multicolumn{4}{|l|}{ Predisposing Factors } \\
\hline \multicolumn{4}{|l|}{ Age } \\
\hline $65,+$ yrs. vs $50-64$ yrs & 4.65 & {$[2.10,10.2]$} & $* * *$ \\
\hline \multicolumn{4}{|l|}{ Gender } \\
\hline Female vs Men & 0.71 & {$[0.36,1.41]$} & \\
\hline \multicolumn{4}{|l|}{ Race + Ethnicity } \\
\hline Other vs White & 1.54 & {$[0.78,3.05]$} & \\
\hline \multicolumn{4}{|l|}{ Enabling Factors } \\
\hline \multicolumn{4}{|l|}{ Marital Status } \\
\hline Other vs Married & 1.02 & {$[0.46,2.26]$} & \\
\hline \multicolumn{4}{|l|}{ Education } \\
\hline $\mathrm{LTHS} v \mathrm{~V}>\mathrm{HS}$ & 0.08 & {$[0.02,0.26]$} & $* * *$ \\
\hline $\mathrm{HS}$ vS $>\mathrm{HS}$ & 0.29 & {$[0.10,0.80]$} & $*$ \\
\hline \multicolumn{4}{|l|}{ Insurance } \\
\hline Public vs others & 0.89 & {$[0.28,2.81]$} & \\
\hline \multicolumn{4}{|l|}{ Poverty Status } \\
\hline $\begin{array}{l}\text { Mid Inc./High Inc. vs } \\
\text { Poor/Near Poor }\end{array}$ & 1.87 & {$[0.87,4.01]$} & \\
\hline \multicolumn{4}{|l|}{ Need Factors } \\
\hline \multicolumn{4}{|l|}{ Pain } \\
\hline Quite/Extreme vs No pain & 1.20 & {$[0.39,3.67]$} & \\
\hline Little/Moderate vs No pain & 1.99 & {$[0.60,6.65]$} & \\
\hline \multicolumn{4}{|l|}{ Perceived Physical Health Status } \\
\hline Good vs Ex/vgood & 0.56 & {$[0.10,3.02]$} & \\
\hline Fair/poor vs Ex/vgood & 0.65 & {$[0.21,2.01]$} & \\
\hline \multicolumn{4}{|l|}{ Perceived Mental Health Status } \\
\hline Good vs Ex/vgood & 4.55 & {$[2.37,8.72]$} & $* * *$ \\
\hline Fair/poor vs Ex/vgood & 4.05 & {$[1.69,9.73]$} & ** \\
\hline \multicolumn{4}{|l|}{ ADL Disability } \\
\hline Yes vs No & 1.68 & {$[0.64,4.37]$} & \\
\hline \multicolumn{4}{|l|}{ IADL Disability } \\
\hline Yes vs No & 1.62 & {$[0.58,4.49]$} & \\
\hline \multicolumn{4}{|l|}{ Functional Disability } \\
\hline Yes vs No & 0.20 & {$[0.05,0.84]$} & * \\
\hline \multicolumn{4}{|l|}{ Activities Disability } \\
\hline Yes vs No & 3.60 & {$[0.97,13.2]$} & \\
\hline \multicolumn{4}{|l|}{ Chronic Disease Groups } \\
\hline One vs None & 0.64 & {$[0.22,1.86]$} & \\
\hline Two vs None & 1.00 & {$[0.34,2.98]$} & \\
\hline Three or more vs None & 0.21 & {$[0.08,0.52]$} & *** \\
\hline \multicolumn{4}{|l|}{ CVD } \\
\hline Yes vs No & 0.02 & {$[0.00,1.12]$} & \\
\hline
\end{tabular}

Table 4 Logistic Regression among Stroke Survivors with Co-occurring Depression in terms of Depression Treatment Medical Expenditure Panel Survey (2002-2012) (Continued)

\begin{tabular}{lccc}
\hline & AOR & $95 \% \mathrm{Cl}$ & $\mathrm{Sig}$ \\
\hline Anxiety & & & \\
$\quad$ Yes vs No & 0.88 & {$[0.38,2.01]$} & \\
Hyperlipidemia & & \\
$\quad$ Yes vs No & 1.55 & {$[0.82,2.93]$}
\end{tabular}

Personal Health Practices Factors

BMI Status

Smoking Status

Curr smoker vs Other

External Environmental Factors

Metropolitan Status

Non-Metropolitan vs Metropolitan $1.64 \quad[0.77,3.49]$

Region

$\begin{array}{lll}\text { Mid-west vs Northeast } & 2.80 & {[0.86,9.14]} \\ \text { South vs Northeast } & 0.60 & {[0.22,1.66]} \\ \text { West vs Northeast } & 0.41 & {[0.10,1.78]}\end{array}$

Based on 370 older adults (age $\geq 50$ years) with self-reported stroke and depression who were alive during the calendar year $(2002,2004,2006,2008$, 2010, and 2012)

Abbreviations- yrs. years, LT HS Less than High School, HS High School, Wt\% Weighted percentage, Sig Significant difference, Ex/vgood Excellent or Very Good, ADL Activity of Daily Living, IADL Instrumental Activity of Daily Living, Und/normal Underweight or Normal, Overwt/Obese Overweight or Obese, BMI Body Mass Index, AOR Adjusted odds ratio, Mid Inc./High Inc. Middle Income or High Income

Asterisks represent statistical significance group differences by type of treatment (any form of depression treatment and no depression treatment) compared to the reference group based on binomial logistic regression. The reference group for the dependent variable in the binomial logistic regression was "No Depression Treatment"

${ }^{* * *} p<0.001 ; *{ }^{*} 0.001 \leq p<0.01 ; * 0.01 \leq p<0.05$

pharmacologic versus non-pharmacologic treatment modality is complicated and depends on several factors. For example, the choice of antidepressant treatment is generally influenced by the presence of multimorbidity, polypharmacy, and predisposition to antidepressant adverse effects [62]. In this context, non-pharmacologic treatment options (such as cognitive behavioral therapy) may present a favorable alternative. However, nonpharmacologic interventions are expensive, time consuming and usually show delayed response [62]. Thus, from a healthcare practice and policy perspective, it may be prudent to carefully weigh these different factors along with patient preferences, which has the potential to improve adherence and outcomes associated with these depression treatment modalities.

In certain cases, no depression treatment option is adopted among stroke survivors with co-occurring depression. In our study, not reporting any form of depression treatment among stroke survivors with co- 
occurring depression can be due to several reasons such as patient and/or physician preference, suboptimal detection of depression, depression therapy discontinuation due to adverse effects, non-adherence to depression therapy, or the possibility of improvement or remission of depressive symptoms. Future studies are warranted to understand the factors associated with no depression treatment in this vulnerable population.

In terms of predisposing factors, the current study showed that older adults (age $\geq 65$ years) in the study sample were more likely to receive antidepressant therapy compared to those within 50-64 years of age. This finding can be partially explained by the overall increase in antidepressant use among older adults in the US from $3 \%$ in 1988-1994 [63] to 13.7\% during 2007-2010 [64]. Moreover, a study of veterans who survived stroke with an average age of 69.4 years found it was clinically beneficial when patients were dispensed an antidepressant medication [65]. However, caution should be taken with the use of antidepressants in older adults, as with increasing age the chances of developing serotonin syndrome, falls and fractures risk, and mortality increases [58].

With respect to enabling factors, it was observed that stroke survivors with co-occurring depression with lower levels of education had less likelihood of receiving antidepressant therapy or combination therapy. This may be because lower levels of education are consistently associated with limited health literacy [66] and this may lead to less preventative care seeking behavior [67]. Appropriate interventions are required to improve health literacy as individuals with low literacy usually experience 1.5 to 3 times higher chances of poor health outcomes [68]. The current study also observed that stroke survivors with cooccurring depression who belonged to high or middle income status were more likely to receive combination therapy compared to individuals with lower incomes. This finding is not surprising as existing literature suggests that adults from low-income households have several barriers (lack of transport, childcare, health insurance, and difficult working hours) to accessing mental health services such as psychotherapy [69].

In terms of need factors, good and fair/poor perceived mental health status was associated with increased likelihood of antidepressant and combination therapy use. This study finding is consistent with an existing study by Olfson et al. (2006) [70], where longer-term antidepressant use was observed to be associated with perceived fair or poor mental health status, which can be partially attributed to greater motivation from these individuals or their caregivers. In the current study it was observed that having functional disability was associated with lower likelihood of antidepressant use. This finding is counterintuitive as existing double-blind randomized study demonstrated that antidepressant treatment was associated with improved recovery from disability among stroke survivors [71]. Future studies should explore the factors associated with the lower chances of antidepressant use among those with functional disability. Having three or more chronic diseases was associated with lower likelihood of receiving antidepressant treatment. Multiple factors could explain this finding such as competing demands from other disease conditions [72], risk of adverse events (such as falls) with polypharmacy including antidepressants [73] and drug interactions [74, 75].

In the domain of Personal Health Practices factors, both BMI and smoking status were significantly associated with higher likelihood of receiving antidepressant and combination therapy. The positive association of overweight or obese individuals with depression treatment can be explained by the fact that overweight adults are at an increased risk of depression [76], and that maybe the reason they are reporting higher depression treatment. However, caution should be taken while choosing antidepressants among overweight or obese individuals as some antidepressants (such as SSRIs) have been shown to be associated with abdominal obesity [77]. The present study finding suggests that current smokers had significantly higher likelihood of reporting antidepressants and combination therapy, which is not unexpected as adult smokers with depression smoke heavily [78] and may have higher need to treat depression to reduce smoking. Some antidepressants (such as bupropion) are used for smoking cessation and have been found to be effective in long-term smoking cessation [79], but in the present study population only $15 \%$ of current smoker reported using bupropion.

In terms of the external environmental factors, it was surprising to observe that stroke survivors with cooccurring depression who resided in rural areas were more likely to report combination therapy use compared to those residing in metropolitan areas. This finding is inconsistent with existing literature [80, 81], and reason is unclear as there was no significant differences among the study sample residing in metropolitan and rural areas in terms of perceived mental health status, functional disability, and chronic diseases. Future research is warranted to explore the reasons for this difference in metropolitan status. Another interesting finding from this study is that stroke survivors with co-occurring depression residing in Southern region were less likely to report combination therapy use. This is surprising because Southern region is the stroke belt of US and also as per the Darthmouth Atlas of Medicare Prescription Drug use, newer antidepressants use was concentrated in the Southern region [82].

Use of a nationally representative sample of communitydwelling older adults with stroke and co-occurring depression and use of a broad set of individual-level variables including pain, are some of the strengths of this study. 
However, limitations of this study need to be kept in mind while interpreting the findings. MEPS uses self-reported data that are subject to potential recall bias. However, in order to minimize recall bias, interviews are conducted at regular intervals of 4-5 months by MEPS [20]. Sequence of stroke and depression (whether stroke preceded depression or vice-versa) cannot be obtained from the Medical Conditions file. Severity of stroke and depression is unavailable in MEPS data. It cannot be ascertained from MEPS whether psychotherapy was used specifically for depression or for other conditions (such as anxiety). This is also true for antidepressant use (whether it is specific for depression or it was for other conditions such as anxiety, sleep or appetite stimulation). Inability of establishing causeeffect relationship remains one of the inherent drawbacks of studies utilizing secondary data and hence limitations such as the exact reason for using any pharmacologic or non-pharmacologic option remains elusive. MEPS publically available data provide three digit ICD-9-CM codes that can lead to misclassification bias, however, stroke and depression ICD-9-CM codes used in this study have been validated and used in previous studies utilizing MEPS data. One of the other limitations of this study was that we were not able to segregate stroke subtypes (ischemic and hemorrhagic) as individuals with co-occurring hemorrhagic stroke and depression $(n=3)$ was extremely small. And finally, given the range of years of data (2002-2012) used in this study, it may not represent the current status of depression treatment among stroke survivors in the US.

\section{Conclusions}

Despite the limitations, this is the first study to date to provide national level estimates of depression treatment among community-dwelling older adults with stroke and cooccurring depression. Nearly $90 \%$ of the study sample received some form of depression treatment, with SSRIs reported as the most widely used class of antidepressant, and sertraline being the most reported individual antidepressant agent. Use of depression treatment was associated with several individual-level factors such as age, education, poverty status, perceived mental health status, functional disability, presence of other chronic conditions, BMI, smoking, metropolitan status, and region. Future longitudinal studies are warranted to assess the comparative treatment benefits of antidepressants (classes as well as individual antidepressants), psychotherapy and their combination that can add to the current knowledgebase and eventually improve different domains of quality of care (such as effectiveness, safety and patient centeredness). Future studies should also assess the incremental healthcare expenditures among stroke survivors due to the presence of depression and also if depression treatment reduces healthcare expenditure in this vulnerable population.

\section{Additional file}

Additional file 1: Detailed Multum Lexicon codes used to identify sub-classes of antidepressants. Table S1. Multum Lexicon Therapeutic Class Code. (DOCX $12 \mathrm{~kb}$ )

\section{Abbreviations}

ADL: Activity of Daily Living; AHRQ: Agency for Healthcare Research and Quality; AOR: Adjusted Odds Ratio; BMl: Body mass index; Cl: Confidence Intervals; IADL: Instrumental Activity of Daily; ICD-9-CM: International Classification of Diseases, 9th Edition, Clinical Modification; MAOI: MonoAmine Oxidase Inhibitors; MEPS: Medical Expenditure Panel Survey; MEPSHC: Medical Expenditure Panel Survey-Household Component; MEPSIC: Medical Expenditure Panel Survey-Insurance Component; NDC: National Drug Code; NHIS: National Health interview Survey; OR: Odds Ratio; PPAZ: Phenylpiperazine Antidepressants]; RCT: Randomized Controlled Trial; SNRI: Serotonin-Norepinephrine Reuptake Inhibitor; SSRI: Selective Serotonin Reuptake Inhibitor; TCA: Tricyclic Antidepressants; US: United States;

WHI: Women's Health Initiative

\section{Acknowledgements}

A part of this research was presented as poster at the International Society for Pharmacoeconomics and Outcomes Research 22nd Annual International Meeting (May 20-24, 2017; Boston, MA, USA). The authors would like to thank Ms. Zufan Yegezu for her help with formatting of this manuscript.

\section{Funding}

This research did not receive any grant from funding agencies in the public, commercial, or not-for-profit sectors.

Availability of data and materials

The data used in this study was publically available.

\section{Authors' contributions}

SB conceptualized the study, conducted analysis, drafted manuscript, and incorporated suggestion from co-authors in successive iterations. MAY and SK conducted literature review, drafted manuscript, and provided input on successive versions of the manuscript. DRA drafted manuscript, interpreted findings and provided input on successive versions of the manuscript. All authors read and approved the final manuscript.

Ethics approval and consent to participate

This study was approved by The University of Arizona Institutional Review Board as Not Human Subjects Research.

\section{Competing interests}

The views and opinions expressed in this article are those of the authors and do not necessarily reflect the official policy or position of The University of Arizona or any other affiliated organizations. The author(s) declare that they have no competing interests.

\section{Publisher's Note}

Springer Nature remains neutral with regard to jurisdictional claims in published maps and institutional affiliations.

\section{Author details \\ ${ }^{1}$ Department of Pharmacy Practice and Science, College of Pharmacy, The University of Arizona, 1295 North Martin Avenue, Tucson, AZ 85721, USA. ${ }^{2}$ Health Outcomes \& PharmacoEconomic Research (HOPE) Center, College of Pharmacy, The University of Arizona, Tucson, AZ, USA.}

Received: 18 October 2016 Accepted: 4 May 2018 Published online: 16 May 2018

\section{References}

1. Mozaffarian D, Benjamin EJ, Go AS, Arnett DK, Blaha MJ, Cushman M, Das SR, de Ferranti S, Despres JP, Fullerton HJ, et al. Heart disease and stroke Statistics-2016 update: a report from the American Heart Association. Circulation. 2016;133(4):e38-60 
2. Hadidi N, Treat-Jacobson DJ, Lindquist R. Poststroke depression and functional outcome: a critical review of literature. Heart \& lung : the journal of critical care. 2009;38(2):151-62.

3. de Man-van Ginkel JM, Hafsteinsdottir TB, Lindeman E, Ettema RG, Grobbee DE, Schuurmans MJ. In-hospital risk prediction for post-stroke depression: development and validation of the post-stroke depression prediction scale. Stroke. 2013;44(9):2441-5.

4. Robinson RG, Jorge RE. Post-stroke depression: a review. Am J Psychiatry. 2016;173(3):221-31.

5. Sinyor D, Amato P, Kaloupek DG, Becker R, Goldenberg M, Coopersmith $H$. Post-stroke depression: relationships to functional impairment, coping strategies, and rehabilitation outcome. Stroke. 1986;17(6):1102-7.

6. Guajardo VD, Terroni L, Sobreiro Mde F, Zerbini MI, Tinone G, Scaff M, losifescu DV, de Lucia MC, Fraguas R. The influence of depressive symptoms on quality of life after stroke: a prospective study. Journal of stroke and cerebrovascular diseases : the official journal of National Stroke Association. 2015;24(1):201-9.

7. Boden-Albala B, Litwak E, Elkind MS, Rundek T, Sacco RL. Social isolation and outcomes post stroke. Neurology. 2005;64(11):1888-92.

8. Morris PL, Robinson RG, Andrzejewski P, Samuels J, Price TR. Association of depression with 10-year poststroke mortality. Am J Psychiatry. 1993; 150(1):124-9.

9. Lipsey JR, Robinson RG, Pearlson GD, Rao K, Price TR. Nortriptyline treatment of post-stroke depression: a double-blind study. Lancet (London, England). 1984;1(8372):297-300.

10. Andersen $G$, Vestergaard K, Lauritzen L. Effective treatment of poststroke depression with the selective serotonin reuptake inhibitor citalopram. Stroke. 1994;25(6):1099-104.

11. Mitchell PH, Veith RC, Becker KJ, Buzaitis A, Cain KC, Fruin M, Tirschwell D, Teri L. Brief psychosocial-behavioral intervention with antidepressant reduces poststroke depression significantly more than usual care with antidepressant: living well with stroke: randomized, controlled trial. Stroke. 2009;40(9):3073-8.

12. Williams LS, Kroenke K, Bakas T, Plue LD, Brizendine E, Tu W, Hendrie H. Care management of poststroke depression: a randomized, controlled trial. Stroke. 2007;38(3):998-1003.

13. Rampello L, Alvano A, Chiechio S, Raffaele R, Vecchio I, Malaguarnera M. An evaluation of efficacy and safety of reboxetine in elderly patients affected by "retarded" post-stroke depression. A random, placebo-controlled study. Arch Gerontol Geriatr. 2005;40(3):275-85.

14. Fruehwald S, Gatterbauer E, Rehak P, Baumhackl U. Early fluoxetine treatment of post-stroke depression-a three-month double-blind placebo-controlled study with an open-label long-term follow up. J Neurol. 2003;250(3):347-51.

15. Hackett ML, Anderson CS, House A, Xia J. Interventions for treating depression after stroke. Cochrane Database Syst Rev. 2008;(4):CD003437. https://doi.org/10.1002/14651858.CD003437.pub3. Review. PubMed PMID: 18843644.

16. Xu XM, Zou DZ, Shen LY, Liu Y, Zhou XY, Pu JC, Dong MX, Wei YD. Efficacy and feasibility of antidepressant treatment in patients with post-stroke depression. Medicine (Baltimore). 2016;95(45):e5349.

17. Medical Expenditure Panel Survey. MEPS-HC Sample Design and Data Collection Process [http://meps.ahrq.gov/mepsweb/survey_comp/hc_data_ collection.jsp]. Accessed 12 July 2017.

18. Sommers J. An Examination of State Estimates Using Multiple Years of Data from the Medical ExpenditurePanel Survey, Household Component [http:// meps.ahrq.gov/mepsweb/data_files/publications/workingpapers/wp_06004. pdf]. Accessed 12 July 2017.

19. Medical Expenditure Panel Survey. MEPS Survey Background [http://meps. ahrq.gov/mepsweb/about_meps/survey_back.jsp]. Accessed 12 July 2017.

20. Machlin S, Cohen J, Elixhauser A, Beauregard K, Steiner C. Sensitivity of household reported medical conditions in the medical expenditure panel survey. Med Care. 2009;47(6):618-25.

21. Ma JWE, Siegel RL, Jemal A. Temporal trends in mortality in the United States, 1969-2013. JAMA. 2015;314(16):1731-9.

22. Benjamin EJ, Blaha MJ, Chiuve SE, Cushman M, Das SR, Deo R, de Ferranti SD, Floyd J, Fornage M, Gillespie C, et al. Heart disease and stroke Statistics2017 update: a report from the American Heart Association. Circulation. 2017;135(10):e146-603.

23. McCormick N, Bhole V, Lacaille D, Avina-Zubieta JA. Validity of diagnostic codes for acute stroke in administrative databases: a systematic review. PLoS One. 2015;10(8):e01358e34.
24. Atkins EVSU, Bhattacharya R. Variations of depression treatment among women with hypertension. Healthcare for Women International. 2015;36(6):20.

25. Harman JS, Kelleher KJ, Reynolds CF, Pincus HA. Out-of-pocket healthcare expenditures of older Americans with depression. J Am Geriatr Soc. 2004; 52(5):809-13.

26. Bhattacharjee S, Oh YM, Reiman EM, Burke WJ. Prevalence, patterns, and predictors of depression treatment among community-dwelling elderly individuals with dementia in the United States. Am J Geriatr Psychiatry. 2017:25(7):803-13.

27. Nagar S, Sherer JT, Chen H, Aparasu RR. Extent of functional impairment in children and adolescents with depression. Curr Med Res Opin. 2010;26(9): 2057-64.

28. Harman JSEM, Fortney JC, Kallas H. The influence of comorbid chronic medical conditions on the adequacy of depression care for older Americans. J Am Geriatr Soc. 2005;53(12):6.

29. Andersen RM. Revisiting the behavioral model and access to medical care: does it matter? J Health Soc Behav. 1995;36(1):1-10.

30. DI Verdu B, Buclin T, Stiefel F, Berney A. Antidepressants for the treatment of chronic pain. Drugs. 2008;68(18):22.

31. MEPS HC-155 2012 Full Year Consolidated Data File. September 2014.MEPS Data Documentation: Pain definition 2012 [http://meps.ahrq.gov/mepsweb/ data_stats/download_data/pufs/h155/h155doc.pdf]. Accessed 14 July 2017.

32. Gordon WA, Hibbard MR. Poststroke depression: an examination of the literature. Arch Phys Med Rehabil. 1997;78(6):658-63.

33. Desmaele S, Putman K, De Wit L, Dejaeger E, Gantenbein AR, Schupp W, Steurbaut S, Dupont AG, De Paepe K. A comparative study of medication use after stroke in four countries. Clin Neurol Neurosurg. 2016;148:96-104.

34. Santos EB, Rodrigues RA, Pontes-Neto OM. Prevalence and predictors of post stroke depression among elderly stroke survivors. Arq Neuropsiquiatr. 2016;74(8):621-5.

35. Tsai CS, Wu CL, Hung TH, Chou SY, Su JA. Incidence and risk factors of poststroke depression in patients with acute ischemic stroke: a 1-year prospective study in Taiwan. Biom J. 2016;39(3):195-200.

36. Mutai H, Furukawa T, Nakanishi K, Hanihara T. Longitudinal functional changes, depression, and health-related quality of life among stroke survivors living at home after inpatient rehabilitation. Psychogeriatrics. 2016: 16(3):185-90.

37. Ayis SA, Ayerbe L, Crichton SL, Rudd AG, Wolfe CD. The natural history of depression and trajectories of symptoms long term after stroke: the prospective South London stroke register. J Affect Disord. 2016;194:65-71.

38. Kowalska J, Bojko E, Szczepanska-Gieracha J, Rymaszewska J, Rozek-Piechura K. Occurrence of depressive symptoms among older adults after a stroke in the nursing home facility. Rehabil Nurs. 2016;41(2):112-9.

39. Alghwiri AA. The correlation between depression, balance, and physical functioning post stroke. Journal of stroke and cerebrovascular diseases : the official journal of National Stroke Association. 2016;25(2):475-9.

40. Gyagenda JO, Ddumba E, Odokonyero R, Kaddumukasa M, Sajatovic M, Smyth K, Katabira E. Post-stroke depression among stroke survivors attending two hospitals in Kampala Uganda. Afr Health Sci. 2015;15(4):1220-31.

41. Schottke H, Giabbiconi CM. Post-stroke depression and post-stroke anxiety: prevalence and predictors. Int Psychogeriatr. 2015;27(11):1805-12.

42. Barker-Collo SL. Depression and anxiety 3 months post stroke: prevalence and correlates. Arch Clin Neuropsychol. 2007;22(4):519-31.

43. Broomfield NM, Quinn TJ, Abdul-Rahim AH, Walters MR, Evans JJ. Depression and anxiety symptoms post-stroke/TIA: prevalence and associations in cross-sectional data from a regional stroke registry. BMC Neurol. 2014;14:198.

44. Paolucci S. Epidemiology and treatment of post-stroke depression. Neuropsychiatr Dis Treat. 2008:4(1):145-54.

45. McCarthy MJ, Sucharew HJ, Alwell K, Moomaw CJ, Woo D, Flaherty ML, Khatri P, Ferioli S, Adeoye O, Kleindorfer DO, et al. Age, subjective stress, and depression after ischemic stroke. J Behav Med. 2016;39(1):55-64.

46. Fei K, Benn EK, Negron R, Arniella G, Tuhrim S, Horowitz CR. Prevalence of depression among stroke survivors: racial-ethnic differences. Stroke. 2016; 47(2):512-5.

47. Mead GE, Hsieh CF, Lee R, Kutlubaev M, Claxton A, Hankey GJ, Hackett M. Selective serotonin reuptake inhibitors for stroke recovery: a systematic review and meta-analysis. Stroke. 2013:44(3):844-50.

48. Wang MT, Chu CL, Yeh CB, Chang LC, Malone DC, Liou JT. Antidepressant use and risk of recurrent stroke: a population-based nested case-control study. The Journal of clinical psychiatry. 2015;76(7):e877-85. 
49. Halperin D, Reber G. Influence of antidepressants on hemostasis. Dialogues Clin Neurosci. 2007;9(1):47-59.

50. Schins A, Hamulyak K, Scharpe S, Lousberg R, Van Melle J, Crijns H, Honig A. Whole blood serotonin and platelet activation in depressed post-myocardial infarction patients. Life Sci. 2004;76(6):637-50.

51. Laghrissi-Thode F, Wagner WR, Pollock BG, Johnson PC, Finkel MS. Elevated platelet factor 4 and beta-thromboglobulin plasma levels in depressed patients with ischemic heart disease. Biol Psychiatry. 1997;42(4):290-5.

52. Smoller JW, Allison M, Cochrane BB, Curb JD, Perlis RH, Robinson JG, Rosal MC, Wenger NK, Wassertheil-Smoller S. Antidepressant use and risk of incident cardiovascular morbidity and mortality among postmenopausal women in the Women's Health Initiative study. Arch Intern Med. 2009; 169(22):2128-39.

53. Mead G, Hackett ML, Lundstrom E, Murray V, Hankey GJ, Dennis M. The FOCUS, AFFINITY and EFFECTS trials studying the effect(s) of fluoxetine in patients with a recent stroke: a study protocol for three multicentre randomised controlled trials. Trials. 2015:16:369.

54. Xian Y, O'Brien EC, Fonarow GC, Olson DM, Schwamm LH, Hannah D, Lindholm B, Maisch L, Lytle BL, Greiner MA, et al. Patient-centered research into outcomes stroke patients prefer and effectiveness research: implementing the patient-driven research paradigm to aid decision making in stroke care. Am Heart J. 2015;170(1):36-45. 45 e31-11

55. Spalletta G, Caltagirone C. Sertraline treatment of post-stroke major depression: an open study in patients with moderate to severe symptoms. Funct Neurol. 2003;18(4):227-32.

56. Tan S, Huang X, Ding L, Hong H. Efficacy and safety of citalopram in treating post-stroke depression: a meta-analysis. Eur Neurol. 2015;74(3-4): 188-201.

57. Zittel S, Weiller C, Liepert J. Citalopram improves dexterity in chronic stroke patients. Neurorehabil Neural Repair. 2008;22(3):311-4.

58. Coupland C, Dhiman P, Morriss R, Arthur A, Barton G, Hippisley-Cox J. Antidepressant use and risk of adverse outcomes in older people: population based cohort study. BMJ. 2011;343:d4551.

59. Wei W, Sambamoorthi U, Olfson M, Walkup JT, Crystal S. Use of psychotherapy for depression in older adults. Am J Psychiatry. 2005;162(4): 711-7.

60. Olfson M, Marcus SC. National trends in outpatient psychotherapy. Am J Psychiatry. 2010;167(12):1456-63.

61. Lincoln NB, Flannaghan T. Cognitive behavioral psychotherapy for depression following stroke: a randomized controlled trial. Stroke. 2003; 34(1):111-5.

62. Lokk J, Delbari A. Management of depression in elderly stroke patients. Neuropsychiatr Dis Treat. 2010;6:539-49.

63. National Center for Health S: Health, United States. Health, United States, 2013: with special feature on prescription drugs. Hyattsville (MD): National Center for Health Statistics (US); 2014.

64. Pratt LA, Brody DJ, Gu Q. Antidepressant use in persons aged 12 and over: United States, 2005-2008. NCHS data brief. 2011;76:1-8.

65. Ried LD, Tueth MJ, Jia H. A pilot study to describe antidepressant prescriptions dispensed to veterans after stroke. Research in social \& administrative pharmacy : RSAP. 2006;2(1):96-109.

66. Paasche-Orlow MK, Parker RM, Gazmararian JA, Nielsen-Bohlman LT, Rudd RR. The prevalence of limited health literacy. J Gen Intern Med. 2005;20(2): $175-84$

67. Institute of Medicine Committee on Health L. In: Nielsen-Bohlman L, Panzer AM, Kindig DA, editors. Health literacy: a prescription to end confusion. Washington (DC): National Academies Press (US) Copyright 2004 by the National Academy of Sciences. All rights reserved; 2004.

68. Dewalt DA, Berkman ND, Sheridan S, Lohr KN, Pignone MP. Literacy and health outcomes: a systematic review of the literature. J Gen Intern Med. 2004;19(12):1228-39.

69. Santiago CD, Kaltman S, Miranda J. Poverty and mental health: how do low-income adults and children fare in psychotherapy? J Clin Psychol. 2013: 69(2):115-26.

70. Olfson M, Marcus SC, Tedeschi M, Wan GJ. Continuity of antidepressant treatment for adults with depression in the United States. Am J Psychiatry. 2006;163(1):101-8.

71. Mikami K, Jorge RE, Adams HP Jr, Davis PH, Leira EC, Jang M, Robinson RG Effect of antidepressants on the course of disability following stroke. Am J Geriatr Psychiatry. 2011;19(12):1007-15.
72. Rost K, Nutting P, Smith J, Coyne JC, Cooper-Patrick L, Rubenstein L. The role of competing demands in the treatment provided primary care patients with major depression. Arch Fam Med. 2000;9(2):150-4.

73. Richardson K, Bennett K, Kenny RA. Polypharmacy including falls riskincreasing medications and subsequent falls in community-dwelling middle-aged and older adults. Age Ageing. 2015;44(1):90-6.

74. Spina E, Santoro V, D'Arrigo C. Clinically relevant pharmacokinetic drug interactions with second-generation antidepressants: an update. Clin Ther. 2008;30(7):1206-27.

75. Greenblatt DJ, von Moltke LL, Harmatz JS, Shader RI. Drug interactions with newer antidepressants: role of human cytochromes P450. The Journal of clinical psychiatry. 1998;59(Suppl 15):19-27.

76. Luppino FS, de Wit LM, Bouvy PF, Stijnen T, Cuijpers P, Penninx BW, Zitman FG. Overweight, obesity, and depression: a systematic review and metaanalysis of longitudinal studies. Arch Gen Psychiatry. 2010;67(3):220-9.

77. Raeder MB, Bjelland I, Emil Vollset S, Steen VM. Obesity, dyslipidemia, and diabetes with selective serotonin reuptake inhibitors: the Hordaland health study. The Journal of clinical psychiatry. 2006;67(12):1974-82.

78. Pratt LA, Brody DJ. Depression and smoking in the U.S. household population aged 20 and over. NCHS data brief. 2005-2008;2010(34):1-8.

79. Hughes JR, Stead LF, Hartmann-Boyce J, Cahill K, Lancaster T. Antidepressants for smoking cessation. The Cochrane database of systematic reviews. 2014;1:CD000031.

80. Rost K, Fortney J, Fischer E, Smith J. Use, quality, and outcomes of care for mental health: the rural perspective. Medical care research and review : MCRR. 2002:59(3):231-65. discussion 266-271

81. Ziller EC, Anderson NJ, Coburn AF. Access to rural mental health services: service use and out-of-pocket costs. The Journal of rural health : official journal of the American Rural Health Association and the National Rural Health Care Association. 2010;26(3):214-24.

82. The Darthmouth Atlas of Medicare Prescription Drug Use. A report of the Darthmouth Atlas Project. http://www.dartmouthatlas.org/downloads/ reports/Prescription_Drug_Atlas_101513.pdf. Accessed 14 July 2017.

\section{Ready to submit your research? Choose BMC and benefit from:}

- fast, convenient online submission

- thorough peer review by experienced researchers in your field

- rapid publication on acceptance

- support for research data, including large and complex data types

- gold Open Access which fosters wider collaboration and increased citations

- maximum visibility for your research: over $100 \mathrm{M}$ website views per year

At BMC, research is always in progress.

Learn more biomedcentral.com/submissions 